\title{
Profiling Research Published in the Journal of Enterprise Information Management (JEIM)
}

\author{
Yogesh K. Dwivedi \\ School of Business \& Economics, Swansea University, Swansea, UK \\ Email: ykdwivedi@gmail.com \\ Navonil Mustafee \\ School of Information Systems, Computing \& Maths, Brunel University, UK \\ Email: navonil.mustafee@brunel.ac.uk
}

\begin{abstract}
:
Purpose - The purpose of this paper is to analyse research published in the Journal of Enterprise Information Management (JEIM) in the last ten years (1999 to 2008).

Design/methodology/approach - Employing a profiling approach, the analysis of the 381 $J E I M$ publications includes examining variables such as the most active authors, geographic diversity, authors' backgrounds, co-author analysis, research methods and keyword analysis.
\end{abstract}

Findings - All the finding are in relation to the period of analysis (1999 to 2008). (a) Research categorised under descriptive, theoretical and conceptual methods is the most dominant research approach followed by JEIM authors. This is followed by case study research. (b) The largest proportion of contributions came from researchers and practitioners with an information systems background, followed by those with a background in business and computer science and IT. (c) The keyword analysis suggests that 'information systems', 'electronic commerce', 'internet', 'logistics', 'supply chain management', 'decision making', 'small to medium-sized enterprises', 'information management', 'outsourcing', and 'modelling' were the most frequently investigated keywords. (d) The paper presents and discusses the findings obtained from the citation analysis that determines the impact of the research published in the JEIM.

Originality/value - The primary value of this paper lies in extending the understanding of the evolution and patterns of IS research. This has been achieved by analysing and synthesising existing $J E I M$ publications.

Keywords: Journal of Enterprise Information Management (JEIM), IS Research, Research Profile

Article Type: Literature Review

\section{Introduction}

The Journal of Enterprise Information Management (JEIM), previously published as Logistics Information Management, is more than 20 years old. It is a well-known Information Systems (IS) research journal. JEIM's reach and its value to IS academics is aptly demonstrated by its inclusion in the journal rankings published by the Association of Business School, Cranfield Business School and Kent Business School. Furthermore, JEIM appears in the journal rankings endorsed by the Australian Council of Professors and Heads of Information Systems. Given its long period in circulation, JEIM has developed and accumulated intellectual assets covering a multitude of IS areas. It is therefore important that this repository of knowledge be methodologically analysed and presented for the benefit of 
the readers. Although it is acknowledged that the JEIM editorials have routinely reflected on the direction of this journal, nevertheless the authors consider that an in-depth analysis encompassing the last ten years of JEIM will be of great interest to the readers since a profiling study usually helps to unearth the intellectual wealth which has evolved during the period of a journal's circulation (Dwivedi et al. 2009).

With reference to journal publications, profiling is considered to be an art of self-examination that aims to benefit a specific audience, and takes a journal towards the right and balanced direction (Dwivedi et al. 2008; 2009; Dwivedi and Kuljis 2008; Palvia et al. 2007). This paper provides an overview of research published in the journal and complements previous work by Avison et al. (2008), Claver et al. (2000), Dwivedi et al. (2008; 2009), Dwivedi and Kuljis (2008) and Palvia et al. (2007) towards understanding and developing the area of IS research. Furthermore, this study is likely to stimulate researchers to profile other IS Journals in order to conduct comparative/cross-journal studies which will ultimately help to understand the overall evolution of the IS discipline (Dwivedi et al. 2008; 2009, Dwivedi and Kuljis 2008).

Before stating the aim and the objectives of this paper it is important to briefly describe efforts in reviewing IS literature by JEIM authors. A search of JEIM publications resulted in a number of review articles on a range of IS topics. A few of the more recent review articles are mentioned here. For example, by undertaking a thorough literature review Parker and Castleman (2009) critique a range of theories for explaining the idiosyncratic nature of small firms and their e-business adoption decisions; Mason et al. (2008) attempt to understand knowledge management, clustering and regional development; Sutton (2006) analyse existing research to establish the basis for the logical formation of a framework for future enterprise risk management research; Mondragon et al. (2006) critically reviewe business trends and drivers affecting the performance of supply chains and build-to-order initiatives; Stockdale and Standing (2004) review benefits and barriers of electronic marketplace participation for SMEs. The publication of these studies indicate that JEIM regularly publishes articles focusing on various facets of IS research evolution. This paper will be a further contribution towards understanding the evolution of the IS discipline from JEIM's perspective.

In light of the above, the aim of this paper is to provide a systematic review of JEIM publications in order to ascertain the current status of its publications. This overall aim is realised through the following seven objectives: (a) to identify the most prolific authors publishing in JEIM; (b) to determine the occupation/position of the contributing authors; (c) to identify authors' backgrounds (i.e. academic or practitioner); (d) to perform co-author analysis; (e) to determine the geographic location of the contributing authors; (f) to classify JEIM publications according to the research methods employed; and (g) to determine the most frequently used keywords in JEIM publications.

These objectives were realised by conducting a systematic review of 381 JEIM articles published during the period 1999-2008. The remainder of this paper is structured as follows. Section 2 provides a discussion of the method employed in the analysis of the published JEIM research. The findings are presented and discussed in Section 3. Finally, Section 4 presents conclusions from this work and the limitations of the approach.

\section{Methodology for Meta-Data Analysis}

Building a profile of the last 10 years of JEIM publications necessitated that the authors systematically review a total of 381 research articles (see Table 1 for number of papers published each year) to capture data on several variables like authors, institutions, etc. Such an approach for the systematic classification of research published in a particular journal is termed as a 'meta-study' or 'longitudinal literature review' (Palvia et al. 2007; Dwivedi and Kuljis 2008; Dwivedi et al. 2008; 2009). This approach has been successfully employed to profile a number of IS and related journals, including the European Journal of Information Systems (EJIS) (Dwivedi and Kuljis 2008), Information \& Management (I\&M) (Claver et al. 2000; Palvia et al. 2007), the Information Systems Journal (ISJ) (Avison et al. 2008), Information Systems Frontiers (ISF) (Dwivedi et al. 2009) and Journal of Electronic 
Commerce Research (JECR) (Dwivedi et al. 2008). It is therefore considered appropriate to use the 'meta-study' approach for JEIM also.

Table 1: Total Number of Articles Published/Year in JEIM between Year 1999 and 2008

\begin{tabular}{|l|c|c|}
\hline \multirow{2}{*}{ Year } & \multicolumn{2}{|c|}{ \# of Publications } \\
\cline { 2 - 3 } & Freq & Percent \\
\hline 1999 & 38 & 9.97 \\
\hline 2000 & 35 & 9.19 \\
\hline 2001 & 39 & 10.24 \\
\hline 2002 & 35 & 9.19 \\
\hline 2003 & 39 & 10.24 \\
\hline 2004 & 34 & 8.92 \\
\hline 2005 & 41 & 10.76 \\
\hline 2006 & 41 & 10.76 \\
\hline 2007 & 40 & 10.50 \\
\hline 2008 & 39 & 10.24 \\
\hline Total & 381 & 100.00 \\
\hline
\end{tabular}

The methodology employed for this profiling study is now described. For each of the 381 articles in our data-set, information was collated for variables such as authors and their backgrounds, geographic regions and countries of authors' affiliated institutions, the research methods employed and the most frequently utilised keywords. The impact of the research was assessed using Google Scholar citation counts. The authors' backgrounds and geographic location variables were adapted from previous studies by Avison et al. (2008) and Dwivedi et al. (2008; 2009). However, consistent with the arguments presented in Dwivedi et al. (2008; 2009), three geographic regions suggested by the Association of Information Systems (AIS) were further divided into seven regions to reflect the true picture of the publication activity from different geographic regions. These regions are as follows: (1) AIS-R1- USA \& Canada; (2) AIS-R1- Other (Latin American \& South American Countries); (3) AIS-R2- Europe \& UK; (4) AIS-R2- Middle East \& Africa; (5) AIS-R3- South Korea, Singapore, Hong Kong, Taiwan, China, Japan, India; (6) AIS-R3- Australia \& New Zealand; (7) AIS-R3- Other.

The research methods employed by the JEIM authors were coded under different categories. These categories were adapted from previous studies by Avison et al. (2008), Chen and Hirschheim (2004), Dwivedi et al. (2008, 2009) and Palvia et al. (2007). These research method categories are as follows: (1) Descriptive/Theoretical/Conceptual; (2) Survey; (3) Experiment; (4) Case Study; (5) Data Analysis; (6) Interview; (7) Ethnographic Studies. The reader is referred to the above-mentioned studies to find detailed information on the research method categories.

Earlier profiling studies have cautioned that the findings with regards to the most active authors and universities with the most contributors should be regarded as indicative and not an authoritative declaration (Claver et al. 2000; Dwivedi and Kuljis 2008; Dwivedi et al. 2008; 2009; Palvia et al. 2007), and this study takes a similar view. The authors agree with the argument presented in the earlier studies that some authors prefer to publish in a specific journal than others and some universities may have niches of research expertise that are not yet visible.

\section{Findings and Discussion}

The findings of this study are now presented under different subsections. Each of the eleven subsections discusses the findings in relation to a particular variable. The variables are as follows: most productive authors (section 3.1), occupation of authors (3.2), area of academic expertise/authors' home department (3.3), authors' background (3.4), co-author analysis (3.5), 
country and geographical regions (3.6), type of publication (3.7), research method employed (3.8), keyword analysis (3.9), citation analysis (3.10), and most downloaded article (3.11).

\subsection{Most Active Authors}

An analysis is conducted to identify those authors who published the most in the 10-year period (1999-2008) in JEIM. Similar to the study by Palvia et al. (2007) and Dwivedi et al. (2008; 2009), for assessing research productivity the normal count approach is employed. For presenting the findings of this study, only those authors who have published three or more articles during the period studied are included in the list. A total of 694 authors contributed to the 307 articles of JEIM. Table 2 lists the 28 most productive authors, ordered according to the number of articles published in JEIM during the study period. The findings suggest that the largest number of articles $(\mathrm{C}=7)$ have been authored by Gunasekaran. Ndubisi, Hong and Love have contributed to six publications each $(\mathrm{C}=6)$ and remain tied in the second position. The third and the fourth positions are occupied by four authors each. The remaining 16 authors in Table 2 each contributed to three articles $(\mathrm{C}=3)$. Although not listed in the Table, 56 authors contributed to two articles each $(\mathrm{C}=2)$ and finally, the largest number of authors (661) contributed to one article each $(\mathrm{C}=1)$.

Table 2: The most productive authors who published three or more papers in JEIM between 1999 and 2008

\begin{tabular}{clcclc}
\hline SL & $\begin{array}{c}\text { Author Name } \\
(\mathrm{n}=746)\end{array}$ & $\begin{array}{c}\text { Count } \\
(\mathrm{N}=381)\end{array}$ & $\mathrm{SL}$ & $\begin{array}{c}\text { Author Name } \\
(\mathrm{n}=746)\end{array}$ & $\begin{array}{c}\text { Count } \\
(\mathrm{N}=381)\end{array}$ \\
\hline 1 & Gunasekaran A & 7 & 15 & Jantan M & 3 \\
2 & Ndubisi NO & 6 & 16 & Hackney R & 3 \\
3 & Hong P & 6 & 17 & Gupta JND & 3 \\
4 & Love PED & 6 & 18 & Bal J & 3 \\
5 & Lee WB & 5 & 19 & Lau HCW & 3 \\
6 & Alshawi S & 5 & 20 & Teo PK & 3 \\
7 & Kahraman C & 5 & 21 & Chung WWC & 3 \\
8 & Irani Z & 5 & 22 & Choy KL & 3 \\
9 & Themistocleous M & 4 & 23 & Fjermestad J & 3 \\
10 & Eldabi T & 4 & 24 & Anumba CJ & 3 \\
11 & Badii A & 4 & 25 & Marri HB & 3 \\
12 & Sharif AM & 4 & 26 & Giaglis GM & 3 \\
13 & Currie WL & 3 & 27 & Ruan D & 3 \\
14 & Rizzi A & 3 & 28 & Baldwin LP & 3 \\
\hline
\end{tabular}

In terms of the most active authors, although the lists provided in previous profiling studies pertaining to the European Journal of Information System (Dwivedi \& Kuljis, 2009) and Information \& Management (Palvia et al. (2007) and in this study includes well known authors, only three authors (Zahir Irani, Peter ED Love and Wendy Currie) appear in both previous studies and in this study. As argued by previous studies (Dwivedi et al. 2008; 2009; Palvia et al. 2007) such a pattern indicates that each journal has their specific author population for generating intellectual wealth by contributing the scholarly articles. Author population for each journal is large but the population of authors who prefer to contribute to specific journals a number of times are few. This might be due to the fact that such authors understand the editorial policies, quality criteria and review process of their preferred journal well that they manage to publish more than two or three articles in the same journals. Thus, future studies reporting findings on the most productive authors based on only one publishing outlet should be cautious when making authoritative claims.

\subsection{Occupation of authors}


The data presented in Table 3 suggests that the highest proportion of JEIM authors hold Lectureships. This is then followed by Professorial positions. An almost equal number of authors were either Assistant Professor $(\mathrm{C}=49,5.6 \%)$ or Associate Professor $(\mathrm{C}=45,5.1 \%)$, followed by authors from industry (i.e. Practitioners) whose role was not possible to specify, and then equal numbers of Senior Lecturers and Researchers. 29 (3.3\%) authors were engaged as Doctoral candidate and then authors with administrative positions such as head of department $(\mathrm{HoD})$ or chair or directors of the centre. Other less frequently reported roles/positions listed in Table 3 include Reader, Visiting Positions, Principal Lecturer, Teaching Fellow/Senior Teaching Fellow and Scientist. It is important to mention that would not able to identify positions of more than half of the authors due to lack of data.

Table 3: Occupation of authors

\begin{tabular}{lcc}
\hline Occupation & Frequency & Percent \\
\hline Lecturer & 76 & 8.6 \\
Professor & 61 & 6.9 \\
Assistant Professor & 49 & 5.6 \\
Associate Professor & 45 & 5.1 \\
Practitioner & 44 & 5.0 \\
Senior Lecturer & 37 & 4.2 \\
Researcher & 37 & 4.2 \\
PhD Candidate & 29 & 3.3 \\
HoD/ChairPerson/Director & 21 & 2.4 \\
Reader & 5 & 0.6 \\
Visiting Positions & 5 & 0.6 \\
Principal Lecturer & 5 & 0.6 \\
Teaching Fellow/Senior Teaching Fellow & 2 & 0.2 \\
Others & 2 & 0.2 \\
Scientist & 1 & 0.1 \\
Total & 419 & 47.5 \\
Missing & 463 & 52.5 \\
Total & 882 & 100 \\
\hline
\end{tabular}

\subsection{Area of academic expertise/authors' home department}

In terms of the number of authors/contributors from different departments, the largest number of contributors were from departments related to Business and Management $(\mathrm{C}=238,27 \%)$, followed by Information Systems/Management Information Systems $(C=187,21.3 \%)$ and Computer Science/Software Engineering/Information Technology $(\mathrm{C}=126,21.1 \%)$, and Engineering $(125,14.2 \%)$. All other departments and their associated frequency are presented in Table 4.

Table 4: Authors' academic background (i.e. home department)

\begin{tabular}{|l|c|c|}
\hline Discipline & Count & Percent \\
\hline Business \& Management & 238 & 27 \\
\hline Building and Architecture & 21 & 2.4 \\
\hline Computer Science/Software Engineering/IT & 126 & 21.1 \\
\hline Engineering & 125 & 14.2 \\
\hline Economics & 24 & 2.7 \\
\hline Information Systems/ MIS & 187 & 21.3 \\
\hline Informatics/Health Informatics & 20 & 14.3 \\
\hline Logistics \& Transportation & 15 & 1.7 \\
\hline Management/MS/OR & 16 & 1.8 \\
\hline Math \& Statistics & 27 & 3.1 \\
\hline Others & 40 & 4.5 \\
\hline
\end{tabular}




\subsection{Background of authors}

Table 5 illustrates the number of contributors from academia and industry. The largest number of contributors were from academia $(\mathrm{C}=802,91.24 \%)$ and a comparatively smaller proportion of authors were from industry $(\mathrm{C}=77,8.76 \%)$.

Table 5: Authors' background

\begin{tabular}{lcc}
\hline Authors' Background & Count & Percent \\
\hline Academia & 802 & 91.24 \\
Practitioner & 77 & 8.76 \\
Total & 879 & 100 \\
\hline
\end{tabular}

\subsection{Co-author analysis}

Findings related to the number of contributing authors are presented next. $21 \%(\mathrm{C}=80)$ of the articles were single author papers, $40.94 \%(\mathrm{C}=156)$ articles had contributions from two authors, $26.51 \%(\mathrm{C}=101)$ articles were co-authored by three authors, $9.19 \%(\mathrm{C}=35)$ articles had four authors, $1.84 \%(\mathrm{C}=7)$ articles were co-authored by five authors, and two articles have six authors each (see Table 6).

Table 6: Pattern of co-authorship of JEIM articles

\begin{tabular}{ccc}
\hline Number of Co-authors & Count & Percent \\
\hline 2 & 156 & 40.94 \\
3 & 101 & 26.51 \\
1 & 80 & 21.00 \\
4 & 35 & 9.19 \\
5 & 7 & 1.84 \\
6 & 2 & 0.52 \\
Total & 381 & 100 \\
\hline
\end{tabular}

\subsection{Country and geographical regions}

Authors affiliated to institutions based in 40 different countries published in JEIM between 1999- 2008 (Table 7). The largest number of contributors were from institutions based in the UK $(\mathrm{C}=248,28.1 \%)$, followed by the USA $(\mathrm{C}=183,20.7 \%)$, Australia $(\mathrm{C}=96,10.9 \%)$ and Hong Kong $(\mathrm{C}=49,5.6 \%)$.

Table 7: Contributors' geographical location

\begin{tabular}{clccclcc}
\hline SL & Country & Count & Percent & SL & Country & Count & Percent \\
\hline 1 & UK & 248 & 28.1 & 22 & UAE & 6 & 0.7 \\
2 & USA & 183 & 20.7 & 23 & Denmark & 6 & 0.7 \\
3 & Australia & 96 & 10.9 & 24 & France & 5 & 0.6 \\
4 & Hong Kong & 49 & 5.6 & 25 & South Africa & 5 & 0.6 \\
5 & Canada & 34 & 3.9 & 26 & Singapore & 4 & 0.5 \\
6 & Turkey & 27 & 3.1 & 27 & Taiwan & 4 & 0.5 \\
7 & Greece & 25 & 2.8 & 28 & Pakistan & 3 & 0.3 \\
8 & Germany & 23 & 2.6 & 29 & Botswana & 2 & 0.2 \\
9 & Italy & 23 & 2.6 & 30 & Egypt & 2 & 0.2 \\
10 & Spain & 18 & 2.0 & 31 & Japan & 2 & 0.2 \\
11 & Malaysia & 14 & 1.6 & 32 & Kuwait & 2 & 0.2 \\
11 & Ireland & 13 & 1.5 & 33 & Poland & 2 & 0.2 \\
13 & Switzerland & 11 & 1.2 & 34 & Romania & 2 & 0.2 \\
14 & Belgium & 10 & 1.1 & 35 & Brazil & 1 & 0.1 \\
15 & The Netherlands & 10 & 1.1 & 36 & Libya & 1 & 0.1 \\
16 & China & 9 & 1.0 & 37 & Norway & 1 & 0.1 \\
17 & Austria & 8 & 0.9 & 38 & Palestine & 1 & 0.1 \\
\hline
\end{tabular}




\begin{tabular}{|c|c|c|c|c|c|c|c|}
\hline 18 & Sweden & 8 & 0.9 & 39 & Portugal & 1 & 0.1 \\
\hline 19 & Finland & 8 & 0.9 & 40 & Russia & 1 & 0.1 \\
\hline 20 & India & 7 & 0.8 & 41 & Total & 882 & 100 \\
\hline 21 & New Zealand & 7 & 0.8 & & & & \\
\hline
\end{tabular}

In terms of the number of authors from different geographical regions (as per the Association of Information Systems [AIS]), the largest number of authors $(\mathrm{C}=450,51 \%)$ were from AIS Region 2 - Europe and UK, followed by authors from AIS Region 1 - USA and Canada $(\mathrm{C}=216,24.5 \%)$, AIS Region 3- Australia \& New Zealand $(\mathrm{C}=103,11.7 \%)$ and AIS Region 3 - South Korea, Singapore, Hong Kong, Taiwan, China, Japan, India $(C=75,8.5 \%)$. The other three AIS regions are also illustrated in Table 8.

Table 8: Geographical regions of JEIM authors

\begin{tabular}{lcc}
\hline Geographical Region (AIS Classification) & Count & Percent \\
\hline AIS-R2-Europe \& UK & 450 & 51.0 \\
AIS-R1-USA \& Canada & 216 & 24.5 \\
AIS-R3-Australia \& New Zealand & 103 & 11.7 \\
AIS-R3-South Korea, Singapore, Hong Kong, Taiwan, China, Japan, & 75 & 8.5 \\
India & 19 & 2.2 \\
AIS-R2-Middle East \& Africa & 18 & 2.0 \\
AIS-R3-Other & 1 & 0.1 \\
AIS-R1-Other (Latin American \& South American Countries) & 882 & 100 \\
Total & \\
\hline
\end{tabular}

Previous studies that have reviewed specific journals like Information Systems Journal (Avison et al. 2008), Journal of Electronic Commerce Research (Dwivedi et al. 2008) and Information Systems Frontiers (Dwivedi et al. 2009) show that regions such as South America, the Middle East, the Former Soviet Union and many underdeveloped countries of Asia are under-represented in terms of undertaking and publishing information systems and electronic commerce research. This study identifies a similar pattern (see Tables 7-8). This skewed representation raises an important research agenda for IS researchers to investigate: whether this situation is a consequence of a global IS digital divide or whether it is due to a lack of interest or lack of necessary expertise to undertake IS research within such countries (Dwivedi et al. 2008; 2009). In either case, the problem of a potential global IS divide needs to be investigated and academics from countries such as the USA, UK, Australia, Hong Kong, Taiwan, Korea, and European countries should consider collaboration with researchers from under-represented regions in order to undertake more fruitful research which is critical to the global emergence of information systems (Dwivedi et al. 2008; 2009).

Such unequal distribution of research output in various journals raises question on the appropriateness of using the AIS Regions for geographical comparison of research output. Dwivedi et al. (2008; 2009) argued that researchers should divide the AIS Region 2 into three sub-divisions, namely European regions, the Middle East and Africa. Similarly, the AIS Region 1 should be divided into North and South America, and the AIS Region 3 should be divided into the Pacific Region (Australia and New Zealand), active Asian nations such as Singapore, Hong Kong, South Korea, Japan, Taiwan, China, and India, and comparatively less active Asian regions such as Afghanistan, Bangladesh, Cambodia, Indonesia, Malaysia, Nepal, Pakistan, Sri Lanka, Thailand, and many other countries. Without such finer divisions it will not be possible to develop a clear picture of the regional growth of information systems and electronic commerce practice and research (Dwivedi et al. 2008; 2009). Profiling of JECR (Dwivedi et al. 2008), ISF (Dwivedi et al. 2009) and JEIM provides empirical evidence that it might be more appropriate to follow the modified classification scheme described above for the purpose of future research.

\subsection{Types of Publications}


The 381 JEIM publications in our data-set are now categorised according to their publication type. These publication types have been identified by the publisher of this journal - Emerald. The data presented in Table 9 illustrate that a vast majority of the publications are 'Research Papers' (C=307), followed by 'Case Study' and 'Viewpoint' papers. The remaining categories with their associated frequency are presented in Table 9.

Table 9: Classification of JEIM Publications According to Publisher (Emerald) Categories

\begin{tabular}{|l|c|c|}
\hline Types of Publications & Freq & Percent \\
\hline Research paper & 307 & 80.6 \\
\hline Case study & 19 & 5.0 \\
\hline Viewpoint & 16 & 4.2 \\
\hline Conceptual Paper & 15 & 3.9 \\
\hline Literature Review & 11 & 2.9 \\
\hline General Review & 8 & 2.1 \\
\hline Technical Paper & 5 & 1.3 \\
\hline Total & 381 & 100 \\
\hline
\end{tabular}

\subsection{Research Methods}

The findings suggest that although a total of 14 different research methods were recorded from our data analysis, the majority of studies employed conceptual/descriptive/theoretical methods $(C=120,31.5 \%)$, followed by case study $(C=95,24.9 \%)$ and survey $(C=64,16.8 \%)$ methods. The other categories with their associated counts and percentage are presented in Table 10.

Table 10: Research methods employed

\begin{tabular}{|l|c|c|}
\hline Research Methods & Count & Percent \\
\hline Conceptual/Descriptive/Theoretical & 120 & 31.5 \\
\hline Case Study & 95 & 24.9 \\
\hline Survey & 64 & 16.8 \\
\hline Interview & 22 & 5.8 \\
\hline Analytical ${ }^{*}$ & 21 & 5.5 \\
\hline Viewpoint/Commentary & 16 & 4.2 \\
\hline Design Research & 11 & 2.9 \\
\hline Secondary Data Analysis & 9 & 2.4 \\
\hline Mixed & 8 & 2.1 \\
\hline Experiment & 5 & 1.3 \\
\hline Content Analysis & 5 & 1.3 \\
\hline Action Research & 2 & .5 \\
\hline Focus Group & 2 & .5 \\
\hline Meta-Analysis & 1 & .3 \\
\hline Total & 381 & 100.0 \\
\hline${ }^{*}$ This category includes various methods such as Simulation, Algorithm, Mathematical Modelling \\
\hline
\end{tabular}

\subsection{Keyword Analysis: Popular Keywords}

A total of 1576 keywords were extracted from the 381 JEIM publications in our data set. The objective was to identify the most frequently used keywords. A total of 61 keywords were used five or more times. These 61 keywords, along with their frequency, are listed in Table 11. 'Information Systems' $(C=74)$, 'Electronic Commerce' $(C=48)$ and "Internet" $(C=43)$ 
were three most frequently used keywords, followed by 'Logistics' and 'Supply Chain Management', each having 38 occurrences. The trend of keyword use suggests that JEIM is a leading outlet of research in the area of information systems, electronic commerce, logistics and supply chain management, knowledge management, outsourcing, business process reengineering and integration.

Table 11: Most frequently used keywords

\begin{tabular}{|l|c|l|l|}
\hline Keywords & \multicolumn{2}{l}{ Kreq } & Kreqwords \\
\hline Information systems & 74 & Management & 7 \\
\hline Electronic commerce & 48 & Organizational change & 7 \\
\hline Internet & 43 & Process management & 7 \\
\hline Logistics & 38 & Purchasing & 7 \\
\hline Supply chain management & 38 & United Kingdom & 7 \\
\hline Information technology & 34 & Value chain & 7 \\
\hline Communication technologies & 29 & Business planning & 6 \\
\hline Manufacturing resource planning & 29 & Case studies & 6 \\
\hline Decision making & 21 & Communication & 6 \\
\hline Small to medium-sized enterprises & 18 & Customer relations & 6 \\
\hline Information management & 17 & Electronic data interchange & 6 \\
\hline Risk management & 16 & Implementation & 6 \\
\hline Knowledge management & 15 & Information & 6 \\
\hline Outsourcing & 15 & Investment & 6 \\
\hline Supply chain & 15 & Security & 6 \\
\hline Modelling & 14 & Small-to-medium-sized enterprises & 6 \\
\hline BPR/Business Process Re-engineering & 14 & Supplier relations & 6 \\
\hline Integration & 13 & Suppliers & 6 \\
\hline Government & 11 & Worldwide web & 6 \\
\hline Innovation & 10 & Change management & 5 \\
\hline Simulation & 10 & China & 5 \\
\hline Supply-chain management & 10 & Construction management & 5 \\
\hline Construction industry & 8 & Contingency planning & 5 \\
\hline Distribution management & 8 & Customer satisfaction & 5 \\
\hline Health care & 8 & Design & 5 \\
\hline Project management & 8 & Evaluation & 5 \\
\hline Australia & 7 & Fuzzy logic & 5 \\
\hline Computer security & 7 & Germany & 5 \\
\hline Computer software & 7 & Strategy & 5 \\
\hline Greece & 7 & Supplier evaluation & 5 \\
\hline Malaysia & 7 & & \\
\hline
\end{tabular}

\subsection{Citation Analysis}

Citation analysis was conducted to determine the research impact of the most influential authors and studies. Citation data pertaining to all 381 JEIM articles were extracted from Google Scholar on May 1, 2009. This data was subsequently updated on June 13, 2009. Data obtained from Google Scholar on total citation count per article suggests that 56 articles received 20 or more citations, 46 articles received between 10 and 19 citations, and two sets of 17 articles were cited nine times and eight times respectively. Citation frequencies for remaining articles are presented in Table 12. 21 studies with larger values of citation counts from each year are listed in Table 16 which includes study with largest count by Beamon (1999) with a 170 citation count (as per Google Scholar). As noted by Dwivedi et al. (2008; 2009), older articles are more likely to have larger numbers of citations, while newer articles are likely to possess lower citation counts. This can be shown by the fact that articles possessing the largest number of citations were published in early volumes of JEIM and very few of the articles from a relatively recent volume had a large citation count. This is not an exceptional case as similar tread was identified by previous studies, including the profiling of 
the Journal of Electronic Commerce Research (Dwivedi et al. 2008) and Information Systems Frontiers (Dwivedi et al. 2009). A brief discussion on articles with more than 30 citations is provided below.

Table 12 Frequency of citation counts of JEIM articles (retrieved May 1, 2008, updated on June 13, 2008)

\begin{tabular}{|c|c|c|c|}
\hline Citation Counts & \# of Studies & Citation Counts & \# of Studies \\
\hline 170 & 1 & 23 & 3 \\
\hline 82 & 1 & 22 & 4 \\
\hline 75 & 1 & 21 & 6 \\
\hline 66 & 1 & 20 & 6 \\
\hline 63 & 1 & 19 & 3 \\
\hline 60 & 2 & 18 & 2 \\
\hline 58 & 1 & 17 & 2 \\
\hline 56 & 1 & 16 & 1 \\
\hline 55 & 1 & 15 & 5 \\
\hline 50 & 1 & 14 & 5 \\
\hline 46 & 3 & 13 & 5 \\
\hline 45 & 2 & 12 & 10 \\
\hline 42 & 1 & 11 & 6 \\
\hline 41 & 1 & 10 & 7 \\
\hline 40 & 1 & 9 & 17 \\
\hline 38 & 1 & 8 & 17 \\
\hline 34 & 1 & 7 & 19 \\
\hline 33 & 1 & 6 & 16 \\
\hline 32 & 3 & 5 & 20 \\
\hline 31 & 2 & 4 & 25 \\
\hline 30 & 2 & 3 & 26 \\
\hline 29 & 3 & 2 & 27 \\
\hline 28 & 1 & 1 & 42 \\
\hline 26 & 2 & 0 & 70 \\
\hline 24 & 2 & Total & 381 \\
\hline
\end{tabular}

Five articles that appeared in the year 1999 received high citation counts. Among these five articles, four appeared in a special issue (Vol. 12 No. 1) on "Methodological aspects of IT/IS investment decision making" (guest editor, Zahir Irani). The issues addressed in these four papers included participative evaluation (Remenyi \& Sherwood-Smith, 1999), understanding IS business value (Cronk \& Fitzgerald, 1999), comparative study on evaluation practices of capital investment (Ballantine \& Stray, 1999) and rethinking the approaches to information systems investment evaluation (Serafeimidis \& Smithson, 1999). The high citation count may reflect the interest generated in this topic within IS academics. This may be due to the high level of project failures that were reported in the news (LASCAD, TARUS etc.) and which might have attracted IS academics to focus and rethink on IS evaluation related topics and associated methodological practices. Another notable contribution that appeared in the year 1999 is a viewpoint article on designing the green supply chain (Beamon, 1999). This has received the largest citation counts $(C=170)$ amongst all the 381 publications analysed by us. The reason for this is that green IT is now enjoying substantial attention from IS academics. However, it is to be noted that in the year 1999 it was not a mature topic and the journal is to be commended for publishing such novel and timely topic. Such viewpoints act as thought stimulators and are subsequently read by an increasing number of scholars. 
Five articles from year 2000 that received high citation counts were clearly focussed on supply chain related issues (Childerhouse \& Towill, 2000), were related to the Internet (Angeles, 2000) or EDI (Chapman et al., 2000), dealt with Business Process Re-engineering (Irani, Z. et al., 2000) and associated technology such as ERP (Al-Mashari \& Zairi, 2000). It is notable that there are five publications (Allen \& Fjermestad, 2001; Bhatt \& Emdad, 2001; Tetteh \& Burn, 2001; van Hooft \& Stegwee, 2001; Warkentin, et al. 2001) from same issue (Vol. 14, Issue 1/2) within this list of most cited papers. The reason for this might be the timeliness of these publications. These five papers appeared in early 2001 issue and all dealt with e-commerce/e-business related issues which nearly coincided with exit of dotcom "boom and bust" phase. This was the time when many practitioners and academics were keen to find out the reasons for the dotcom bust and to learn lessons from them. Consequently, researchers and academics published a large number of studies in a very short period of time and cited any existing study on this topic published during that period. This has implications for editors, reviewers and authors because any publication on emerging topics is likely to yield high number of citations and therefore should be considered important by authors in terms of examining such issues and by editors and reviewers in terms of providing opportunity to get such research published.

Table 13: Most cited (30 or more times) JEIM articles (retrieved May 1, 2009, updated on June 13, 2009)

\begin{tabular}{llcc}
\hline SL & \multicolumn{1}{c}{ Study } & Citation & $\begin{array}{c}\text { \# of } \\
\text { Studies }\end{array}$ \\
\hline 1 & Alshawi S (2001); Shiels et al. (2003) & 30 & 2 \\
2 & Cronk \& Fitzgerald (1999); Baskerville \& Siponen (2002) & 31 & 2 \\
3 & Serafeimidis \& Smithson (1999); Irani et al. (2000) ; Allen \& & 32 & 3 \\
& Fjermestad (2001) & 33 & 1 \\
4 & van Hooft \& Stegwee (2001) & 34 & 1 \\
5 & Jharkharia \& Shankar (2005) & 38 & 1 \\
6 & Cebi \& Bayraktar (2003) & 40 & 1 \\
7 & Stockdale \& Standing (2004) & 41 & 1 \\
8 & Bhatt \& Emdad (2001) & 42 & 1 \\
9 & Buonanno et al. (2005) & 45 & 2 \\
10 & Al-Mashari \& Zairi (2000) & 46 & 3 \\
11 & Childerhouse \& Towill (2000) & 50 & 1 \\
12 & Burn \& Robins (2003) & 55 & 1 \\
13 & Ballantine \& Stray (1999) & 56 & 1 \\
14 & Chapman et al. (2000) & 58 & 1 \\
15 & Warkentin et al. (2001) & 60 & 2 \\
16 & Kahraman et al. (2003) & 63 & 1 \\
17 & Remenyi \& Sherwood-Smith (1999) & 66 & 1 \\
18 & Davenport \& Brooks (2004) & 75 & 1 \\
19 & Tetteh \& Burn (2001) & 82 & 1 \\
20 & Angeles (2000) & 170 & 1 \\
21 & Beamon (1999) & & \\
\hline
\end{tabular}

A conceptual paper by Baskerville \& Siponen (2002) on information security meta-policy for emergent organizations was the only paper from the year 2002 which received a high citation counts (30 or more citations). Clearly this paper has addressed one of the very timely topics and has provided policy implications to emergent organisations. This has made the paper popular among many researchers since it provides them an opportunity to validate such theoretical arguments with empirical data. There are a total of four papers - including two papers (Cebi \& Bayraktar, 2003; Kahraman et al., 2003) from a special issue from the year 2003 - that appear in the list of most cited papers. Burn \& Robins (2003) study on egovernment was an early effort in the area of e-government research, it was subsequently cited by a number of studies that appeared within short period of time. Similarly, a strong 
interest emerged for undertaking research in the area of SMEs, particularly adoption of ICTs. The study conducted by Shiels et al. (2003) is an early effort in this area and this makes it a favourite for researchers to cite it in subsequent studies. A total of four papers that were published in 2004 and 2005 appear in the list of most cited papers. The themes of these papers are supply chain (Davenport \& Brooks, 2004; Jharkharia \& Shankar, 2005) and related areas such as electronic marketplace (Stockdale \& Standing, 2004) and technology (such as ERP) (Buonanno et al. 2005; Davenport \& Brooks, 2004). Among the four papers, three papers focussed upon identifying barriers or factors affecting adoption rate.

The above discussion indicates that in general papers from special issues are likely to be cited more than regular paper. There might be a number of reasons responsible for such a pattern. For example, special issue topics are more timely and topical and generally processed much faster then regular issues papers. A reduced publication cycle consequently increases the chances of citations. However, we observed an exception to this pattern. Volume 12 Number 3, 1999 was a special issue on Y2K problem. But because the Y2K scare never really materialised (largely due to the proactive steps taken by the companies who were "doomed" to be affected), these articles have very low citations.

\subsection{Most Downloaded Articles}

Table 14 provide the list of top 21 most downloaded article since year 2005. These articles are arranged according to their download frequency (decreasing order). Data presented in Table 14 illustrate that majority of most downloaded articles were published after year 2000. There are only four exceptions to this trend (Ballard 1996; Beamon 1999; Gunasekaran et al. 1999; Harwood 1994). We also mapped data presented in Table 14 with data presented in Table 13 on most cited articles. The last column of Table 14 indicates whether the most downloaded articles are also listed as most cited articles along with their citation frequency (presented in Table 13). This comparison suggests that only seven most downloaded articles (out of a total of 21) are also most cited articles. The finding suggests that the number of downloads for a particular article does not necessarily lead to a higher citation count. One of the possible explanations is - an article might be downloaded for exploring its usefulness for a particular problem but a detail examination of article may find it irrelevant to the problem domain, hence may not lead to citation. Considering the comparative data presented in table 14, the authors recommend that the readers should be cautions when interpreting or linking number of downloads with citation frequency of a scholarly publication.

Table 14: Most downloaded (top 21) JEIM articles (Data Source: Emerald Publishing Ltd., July 24, 2009) (Note: Download frequency counted from year 2005 onwards)

\begin{tabular}{|r|l|l|c|l|}
\hline \multicolumn{1}{|c|}{ SL } & \multicolumn{1}{|c|}{$\begin{array}{c}\text { Article Details } \\
\text { Authors \& Year) }\end{array}$} & $\begin{array}{c}\text { Publication Details } \\
\text { Vol., No., pp. }\end{array}$ & $\begin{array}{c}\text { Download } \\
\text { Rank }\end{array}$ & $\begin{array}{c}\text { Most Cited: Yes or } \\
\text { No (See Table 13) }\end{array}$ \\
\hline 1 & Davenport \& Brooks (2004) & $17,1,8-19$ & 1 & Yes (Citations: 66) \\
\hline 2 & Scullin et al. (2004) & $17,6,410-415$ & 2 & No \\
\hline 3 & Choudrie J. (2005) & $18,1,64-78$ & 3 & No \\
\hline 4 & Hutchinson \& Warren (2003) & $16,1,64-73$ & 4 & No \\
\hline 5 & Buonanno et al. (2005) & $18,4,384-426$ & 5 & Yes (Citations: 41) \\
\hline 6 & Stockdale \& Standing (2004) & $17,4,301-311$ & 6 & Yes (Citations: 40) \\
\hline 7 & Møller (2005) & $18,4,483-497$ & 7 & No \\
\hline 8 & Beamon (1999) & $12,4,332-342$ & 8 & Yes (Citations: 170) \\
\hline 9 & Hong et al. (2006) & $19,3,320-333$ & 9 & No \\
\hline 10 & Walters (2006) & $19,3,246-261$ & 10 & No \\
\hline 11 & Cebi \& Bayraktar (2003) & $16,6,395-400$ & 11 & Yes (Citations: 38) \\
\hline 12 & Spathis \& Ananiadis (2005) & $18,2,195-210$ & 12 & No \\
\hline 13 & Gunasekaran et al. (1999) & $12,5,386-394$ & 13 & No \\
\hline 14 & Kuruppuarachchi et al. (2002) & $15,2,126-137$ & 14 & No \\
\hline 15 & Pant \& Ravichandran (2001) & $14,1,85-99$ & 15 & No \\
\hline
\end{tabular}




\begin{tabular}{|r|l|l|c|l|}
\hline 16 & Wieder et al. (2006) & $19,1,13-29$ & 16 & No \\
\hline 17 & Kahraman et al. (2003) & $16,6,382-394$ & 17 & Yes (Citations: 60$)$ \\
\hline 18 & Tetteh \& Burn (2001) & $14,1,171-180$ & 18 & Yes (Citations: 75) \\
\hline 19 & Harwood (1994) & $7,5,30-35$ & 19 & No \\
\hline 20 & Ndubisi et al. (2005) & $18,3,330-349$ & 20 & No \\
\hline 21 & Ballard (1996) & $9,3,11-18$ & 21 & No \\
\hline
\end{tabular}

\section{Conclusions}

The aim of this paper was to analyse the current state of IS research published in JEIM by presenting the results of a systematic and comprehensive review of 381 articles that appeared between the years 1999 and 2008. The paper presented the results along a series of dimensions, for example, most active authors, research impact of published articles, authors' backgrounds, most frequently used keywords, research methodology employed, etc. The following are the main conclusions that have emerged from the analysis presented in this study.

- In terms of most active authors, the list includes only two authors (Zahir Irani and Peter ED Love) who have appeared as most active author in profiling analysis of other leading IS journals including European Journal of Information Systems (Dwivedi and Kuljis 2008) and Information \& Management (Palvia et al. 2007).

- A large proportion of JEIM authors hold lectureship, followed by professors, associate and assistant professors.

- In terms of the home department of JEIM authors, the largest numbers of researchers are from Business and Management discipline followed by MIS/IS backgrounds, Computer Science and Software Engineering, and Engineering disciplines.

- JEIM authorship also includes many practitioners.

- Research published in JEIM shows strong collaborative works. The largest numbers of papers are co-authored by two authors, followed by three author contributions. There are a number of articles co-authored by four, five and six authors.

- UK is the single largest contributor of JEIM authors and their institutions. Consecutively, AIS-R2- Europe and UK emerged as the most dominant region, followed by AIS-R1- USA and Canada.

- The descriptive/theoretical/conceptual methods, followed by case study and survey, were the most dominant research methods utilised by JEIM authors within the span of our study.

- keywords analysis indicated that 'information systems', 'electronic commerce', 'internet', 'logistics' and 'supply chain management' were the most frequently utilised keywords.

- The highest research impact is reported for the paper published by Beamon (1999), followed by Angeles (2000) and Tetteh \& Burn (2001). The research impact was assessed by citations obtained from Google Scholar for all articles published in JEIM.

We anticipate that JEIM readers will find this paper a useful source of information, especially if they wish to learn more about the various facets pertaining to the existing body of published IS research in JEIM.

\section{Reference:}

Allen, E., Fjermestad, J. (2001), "E-commerce marketing strategies: an integrated framework and case analysis", Logistics Information Management, Vol. 14 No. 1/2, pp. 14-23.

Al-Mashari, M., Zairi, M. (2000), "The effective application of SAP R/3: a proposed model 
of best practice", Logistics Information Management, Vol. 13 No. 3, pp. 156-166.

Alshawi, S. (2001), "Logistics in the Internet age: towards a holistic information and processes picture", Logistics Information Management, Vol. 14 No. 4, pp. 235-242.

Angeles, R. (2000), "Revisiting the role of Internet-EDI in the current electronic commerce scene", Logistics Information Management, Vol. 13 No. 1, pp. 45-57.

Avison, D., Dwivedi, Y.K., Fitzgerald, G., Powell, P., (2008), "The beginnings of a new Era: Time to reflect on 17 years of the ISJ", Information Systems Journal, Vol. 18 No. 1, pp. 5-21.

Ballantine, J.A., Stray, S. (1999), "Information systems and other capital investments: evaluation practices compared", Logistics Information Management, Vol. 12 No. 1, pp. 78-93.

Barki, H., Rivard, S., Talbot, J. (1993), "A keyword classification scheme for IS research literature: an update", MIS Quarterly, Vol. 17 No. 2, pp. 209-225.

Baskerville, R., Siponen, M. (2002), "An information security meta-policy for emergent organizations", Logistics Information Management, Vol. 15 No. 5, pp. 337-346.

Beamon, B. (1999), "Designing the green supply chain", Logistics Information Management, Vol. 12 No. 4, pp. 332-342.

Bhatt, G.D., Emdad, A.F. (2001), "An analysis of the virtual value chain in electronic commerce", Logistics Information Management, Vol. 14 No. 1/2, pp. 78-85.

Buonanno, G., Faverio, P., Pigni, F., Ravarini, A., Sciuto, D., Tagliavini, M. (2005), "Factors affecting ERP system adoption: A comparative analysis between SMEs and large companies", Journal of Enterprise Information Management, Vol. 17 No. 1, 11-27.

Burn, J., Robins, G. (2003), "Moving towards e-government: a case study of organisational change processes", Logistics Information Management, Vol. 16 No. 1, pp. 25-35.

Cebi, F., Bayraktar, D. (2003), "An integrated approach for supplier selection", Logistics Information Management, Vol. 16 No. 6, pp. 395-400.

Chapman, P., James-Moore, M., Szczygiel, M., Thompson, D. (2000), "Building Internet capabilities in SMEs", Logistics Information Management, Vol. 13 No. 6, pp. 353361.

Chen, W.S., Hirschheim, R. (2004), "A paradigmatic and methodological examination of information systems research from 1991 to 2001", Information Systems Journal, Vol. 14 No. 3, pp. 197-235.

Childerhouse, P., Towill, D. (2000), "Engineering supply chains to match customer requirements", Logistics Information Management, Vol. 13 No. 6, pp. 337-346.

Clarke, R. (2008), "An Exploratory study of information systems researcher impact", Communications of the Association for Information Systems, Vol. 22, pp. 1-32.

Claver, E., Gonzalez, R., Llopis, J. (2000), "An analysis of research in information systems (1981-1997)", Information \& Management, Vol. 37, pp. 181-195.

Cronk, M.C., Fitzgerald, E.P. (1999), "Understanding "IS business value": derivation of dimensions", Logistics Information Management, Vol. 12 No. 1, pp. 40-49.

Davenport, T.H., Brooks, J.D. (2004), "Enterprise systems and the supply chain”, Journal of Enterprise Information Management, Vol. 17 No. 1, pp.8-19.

Dwivedi, Y. K., Kuljis, J. (2008), "Profile of IS research published in the European Journal of Information Systems", European Journal of Information Systems, Vol. 17 No. 6, pp. 678-693.

Dwivedi, Y.K, Lal, B., Mustafee, N., Williams, M.D. (2009), "Profiling a decade of Information Systems Frontiers' research", Information Systems Frontiers, Vol. 11 No. 1, pp. 87-102.

Dwivedi, Y.K. (2009), "An analysis of e-government research published in Transforming Government: People, Process and Policy (TGPPP)", Transforming Government: People, Process and Policy, Vol. 3, No. 1, pp. 7-15.

Dwivedi, Y.K., Kiang, M., Lal, B., Williams, M.D. (2008), "Profiling Research Published in the Journal of Electronic Commerce Research", Journal of Electronic Commerce Research, Vol. 9 No. 2, pp. 77-91.

Dwivedi, Y.K., Williams, M.D., Venkatesh, V. (2008a), "Guest Editorial: A profile of 
adoption of Information \& Communication Technologies (ICT) research in the household context", Information Systems Frontiers, Vol. 10 No. 4, pp. 385-390.

Irani, Z., Hlupic, V., Baldwin, L.P., Love, P.E.D. (2000), "Re-engineering manufacturing processes through simulation modelling" Logistics Information Management, Vol. 13 No. 1, pp. 7-13.

Jharkharia, S., Shankar, R. (2005), "IT-enablement of supply chains: understanding the barriers", Journal of Enterprise Information Management, Vol. 17 No. 1, 11-27.

Kahraman, C., Cebeci, U., Ulukan, Z. (2003), "Multi-criteria supplier selection using fuzzy AHP”, Logistics Information Management, Vol. 16 No. 6, pp. 382-394.

Mason, C., Castleman, T., Parker, C. (2008), "Communities of enterprise: developing regional SMEs in the knowledge economy", Journal of Enterprise Information Management, Vol. 21 No. 6, pp. 571-584.

Mondragon, A.E.C., Lyons, A.C., Michaelides, Z., Kehoe, D.F. (2006), "Automotive supply chain models and technologies: a review of some latest developments", Journal of Enterprise Information Management, Vol. 19 No. 5, pp. 551 - 562

Palvia, P., Pinjani, P., Sibley, E.H. (2007), "A profile of information systems research published in the Information \& Management", Information \& Management, Vol. 44, pp. 1-11.

Parker, C.M., Castleman, T. (2009), "Small firm e-business adoption: a critical analysis of theory", Journal of Enterprise Information Management, Vol. 22 No. 1/2, pp. 167182.

Remenyi, D., Sherwood-Smith, M. (1999), "Maximise information systems value by continuous participative evaluation", Logistics Information Management, Vol. 12 No. 1, pp. 14-31.

Serafeimidis, V., Smithson, S. (1999), "Rethinking the approaches to information systems investment evaluation", Logistics Information Management, Vol. 12 No. 1, pp. 94107.

Shiels, H., McIvor, R., O'Reilly, D. (2003), "Understanding the implications of ICT adoption: insights from SMEs", Logistics Information Management, Vol. 16 No. 5, pp. 312326.

Stockdale, R., Standing, C. (2004), "Benefits and barriers of electronic marketplace participation: an SME perspective", Journal of Enterprise Information Management, Vol. 17 No. 4, pp. 301-311.

Sutton, S.G (2006), "Extended-enterprise systems' impact on enterprise risk management", Journal of Enterprise Information Management, Vol. 19 No. 1, pp. 97-114.

Tetteh, E., Burn, J. (2001), "Global strategies for SMe-business: applying the SMALL framework", Logistics Information Management, Vol. 14 No. 1/2, pp. 171-180.

van Hooft, F.P.C., Stegwee, R.A. (2001), "E-business strategy: how to benefit from a hype", Logistics Information Management, Vol. 14 No. 1/2, pp. 44-54.

Warkentin, M., Bapna, R., Sugumaran, V. (2001), "E-knowledge networks for interorganizational collaborative e-business", Logistics Information Management, Vol. 14 No. 1/2, pp. 149-163. 